\title{
John Hall Grundy Lecture
}

\author{
Maj Gen J P Crowdy \\ $\mathrm{CB}, \mathrm{QHP}, \mathrm{MB}, \mathrm{ChB}, \mathrm{L} / \mathrm{RAMC}$ \\ Commandant and Post Graduate Dean, Royal Army Medical College
}

\section{Introduction}

Over the last few years Mrs. Hall Grundy, wife of John Grundy whose name we honour today, has sought some means of perpetuating the memory of her husband and the work he did for the Royal Army Medical College. Following discussions with her it was suggested that the best way to do this was to seek the foundation, with an adequate endowment, of an annual lecture. By this means the name of John Hall Grundy will each year be in the forefront of medical entomological thinking and I can imagine no better way of assuring recognition of his name in perpetuity.

Responding to our suggestion Mrs. Grundy has presented to the Royal Army Medical College a beneficent endowment, the income from which will be more than sufficient to fulfil the aims of the bequest, which are:

1. To perpetuate the memory of John Hall Grundy, Lecturer at this College, Artist and Entomologist, by the institution of an annual lecture at the Royal Army Medical College and the award of a presentation medal.

2. To foster and encourage, by means of the annual lecture, increased interest and concern in medical entomology.

We are fortunate indeed that circumstances have so unfolded that we are now able to plan for the annual lecture, confident in the knowledge that we have sufficient funds to fulfil the objectives of the bequest and at the same time to entertain in a suitable manner those with the best interests of entomology at heart.

\section{Footnote:}

At the conclusion of Professor Busvine's lecture the Director General Army Medical Services, Lt Gen Sir Alan Reay KBE QHP presented the speaker with the Grundy Medal, a silver-gilt medal based on the plaque sculptured by Mark Batten and cast by Garrards the Crown Jewellers.

\section{John Hall Grundy -}

An Appreciation

\section{DR N R H BURGESS, PhD, FRES, MIBiol}

Senior Lecturer and Adviser in Entomology to the MOD, Royal Army Medical College

John Grundy studied anatomy at King's College London and art at the Chelsea School before joining the staff of the Royal College of Art. There his $N$ curriculum included colour design, etching and $\frac{1}{N}$ engraving, fine-line block production and printing 0 During this time he made a number of anatomicat studies at the Royal College of Surgeons and later $\bar{\alpha}$. the Orpington War Hospital.

In 1942, having spent a short time studying undex Professor Buxton at the London School of Hygien he joined the Royal Army Medical College and took up a post in the Department of Tropical Medicine $\stackrel{\oplus}{\oplus}$ where he remained as Lecturer in Entomology when the 2nd World War ended. I joined his staff in 196. intending to spend 6 months filling in time before going to Birmingham University to study dentistry. John's enthusiasm for his subject so affected me that $\stackrel{\varnothing}{\varnothing}$ long before the 6 months had ended I had resolved to become an entomologist instead! I am delighted to see, among this distinguished audience, General Gordon Morrison who at that time was Professor of Tropical Medicine and whose encouragement and ádvice I very much appreciated. John Grundy retired in 1967, and he and his wife Anne, who has been a driving force behind many of his achievements, now live happily, although regretably not in very good health, at their home near Stockbridge in Hampshire.

Many members of this audience will remember John as a most gifted teacher. $\mathrm{He}$ had the ability to convey the essential facts of his subject in an instructive and entertaining manner, with enormous enthusiasm and a considerable knowledge. But perhaps above all was his particular and unusual skill as an artist. He is a perfectionist in all aspects of his work $\frac{D}{0}$ and I can clearly remember how he would tear up an almost completed drawing which was apparently or inaccurate in some small way, rather than present $N$ an imperfect result. It almost broke the heart of many a student to see him erase from the black- 
board his most exact and finely executed drawings as if they were insignificant doodles.

John's entomological drawings are well-known, but the broader scope of his artistic ability is not perhaps so fully appreciated. An exhibition here at the College in 1976 consisted of over 150 examples of his work and included anatomical studies, scenes from hospital life, animal drawings and publicity material. A small display of his drawings can be seen outside the lecture theatre. For his artistic ability John Grundy was recently awarded an honorary doctorate of Queens University Belfast.

The post of lecturer in entomology was and still is unique in the Royal Army Medical College in being one of the few teaching posts occupied by a civilian. This has the great advantage of ensuring continuity of experience, policy and teaching methods. During his 25 years at the College John Grundy lectured and demonstrated to about 1100 Senior and Junior Army Medical Officers, to nearly 2000 National Service Medical Officers and to a considerable number of laboratory technicians and hygiene assistants.

A great many people within the Army Medical Services are grateful to him for providing them with a basic and essential knowledge of medical entomology. I am particularly grateful to him for laying the foundations of what is now a thriving and integral part of medicine and public health in the Armed Services.

\section{Reflections on Some Human Ectoparasites}

\section{JAMES R. BUSVINE DSc, FIBiol}

The title of this talk being somewhat vague, it may be useful to explain what it will be about. The ectoparasites in question are mainly those with which my researches have been concerned over many years: human lice, the bed bug, fleas and the itch mite. Like John Grundy, my primary concern was to assist in finding ways of controlling these pests, or to instruct others in their biology to facilitate such control efforts. Therefore I ought to spend some time considering the changing situation in this important practical matter. However, I think that in this lecture I may be allowed to discuss certain less obviously practical aspects of the ectoparasites in regard to their specification. For both parts of my talk, some explanation seems due for the bracketing together of these particular anthropods of public health importance; and I will begin with the practical issues.

As you may know, I was for many years a member of the Entomology Department of the London School of Hygiene and Tropical Medicine. The medi- cal entomology courses we taught were mainly concerned with disease vectors and were largely orientated towards the tropics where such diseases are most severe. Of my four kinds of ectoparasite, only of the human body louse is an important disease vector, $\ddot{\vec{z}}$ the others being merely vexations in themselves. $\stackrel{0}{\rightarrow}$ However, the characteristic common to all of them is the fact that they can potentially be eliminated by improvements in personal hygiene. In contrast, $\frac{\bar{S}}{\partial}$ no conceivable improvement in cleanliness or house $\mathbb{\Phi}$ construction could ensure freedom from yellow fever, onchocerciasis or malaria. No one would subscribe to Belloc's tongue-in-cheek rhyme:

How idiotic; can quinine

Replace cold baths and sound hygiene?

But those anthropods which have become adapted to life on our bodies, or permanently resident in our dwellings, are indeed vulnerable to improvements in hygiene. Let us consider what has happened to them over the past years.

\section{Human body lice}

If we could alter the habit of many decades, these should be called clothing lice, since they spend near all their time on clothing, mostly on the garment negy to the skin. This has important consequences. Thuse the monograph on Lice by the late Professor Buxto $\vec{\bullet}$ shows the decline to zero of cases of typhus in Britaif during the nineteenth century. This occurred lons before its connection with lice was demonstrated Nicolle in 1910. The elimination of this dread disease therefore owed nothing to entomologists or even to physicians, but was merely due to the fact that, over the period in question, people came to wash their underwear more frequently and thoroughly. Incidentally, my former colleague John Maunder has pointed out that, in those days, washing clothes entailed boiling them, so that all lice present would be killed, whereas this high temperature is not reached with modern biological washing powders. However, I cannot feel that there is much danger of general lousiness, unless hygienic facilities collapse, as they did for soldiers in the trenches of the First World War.

When a second World War appeared inevitable, Buxton foresaw the possibility of lice spreading among the civilian population, if air raids were to destroy laundering facilities. $\mathrm{My}$ involvement in the subject began when $I$ joined him in a search for 0 lasting protection from lice, which was eventually solved when we got a sample of DDT. This soon $\frac{7}{0}$ proved a marvellous weapon for checking lousebourne disease epidemics in places where low stan- $\mathcal{N}$ dards of hygiene existed. However, while modern $\mathrm{N}$ insecticides have achieved great success in quelling స్ల such epidemics, they cannot be relied upon for 